\title{
Significantly Decreased Mortality in a Large Cohort of Coronavirus Disease 2019 (COVID-19) Patients Transfused Early with Convalescent Plasma Containing High-Titer Anti-Severe Acute Respiratory Syndrome Coronavirus 2 (SARS-CoV-2) Spike Protein IgG
}

Eric Salazar, ${ }^{* \dagger}$ Paul A. Christensen, ${ }^{*}$ Edward A. Graviss, ${ }^{*}$ Duc T. Nguyen, ${ }^{\ddagger}$ Brian Castillo, ${ }^{*}$ Jian Chen, ${ }^{*}$ Bevin V. Lopez, Todd N. Eagar, ${ }^{\dagger \dagger}$ Xin Yi, ${ }^{* \dagger}$ Picheng Zhao, ${ }^{*}$ John Rogers, ${ }^{*}$ Ahmed Shehabeldin, ${ }^{*}$ David Joseph, ${ }^{*}$ Faisal Masud, Christopher Leveque, ${ }^{*}$ Randall J. Olsen, ${ }^{* \dagger}$ David W. Bernard, ${ }^{* \dagger}$ Jimmy Gollihar, ${ }^{\|}$and James M. Musser ${ }^{* \dagger}$

From the Departments of Pathology and Genomic Medicine* and Anesthesiology and Critical Care, ${ }^{\llbracket}$ Houston Methodist Hospital, Houston, Texas; the Department of Pathology and Laboratory Medicine, ${ }^{\dagger}$ Weill Cornell Medical College, New York, New York; the Center for Molecular and Translational Human Infectious Diseases ${ }^{\ddagger}$ and the Academic Office of Clinical Trials, ${ }^{\S}$ Houston Methodist Research Institute, Houston, Texas; and the The Combat Capabilities Development Command Army Research Laboratory-South," University of Texas at Austin, Austin, Texas

Accepted for publication October 28, 2020.

Address correspondence to James M. Musser, M.D., Ph.D., 6565 Fannin St., Suite B490, Houston, TX 77030. E-mail: jmmusser@ houstonmethodist.org.

\begin{abstract}
Coronavirus disease 2019 (COVID-19) convalescent plasma has emerged as a promising therapy and has been granted Emergency Use Authorization by the US Food and Drug Administration for hospitalized COVID-19 patients. We recently reported results from interim analysis of a propensity score-matched study suggesting that early treatment of COVID-19 patients with convalescent plasma containing hightiter anti-spike protein receptor binding domain (RBD) IgG significantly decreases mortality. We herein present results from a 60-day follow-up of a cohort of 351 transfused hospitalized patients. Prospective determination of enzyme-linked immunosorbent assay anti-RBD IgG titer facilitated selection and transfusion of the highest titer units available. Retrospective analysis by the Ortho VITROS IgG assay revealed a median signal/cutoff ratio of 24.0 for transfused units, a value far exceeding the recent US Food and Drug Administration-required cutoff of 12.0 for designation of high-titer convalescent plasma. With respect to altering mortality, our analysis identified an optimal window of 44 hours after hospitalization for transfusing COVID-19 patients with high-titer convalescent plasma. In the aggregate, the analysis confirms and extends our previous preliminary finding that transfusion of COVID-19 patients soon after hospitalization with high-titer anti-spike protein RBD IgG present in convalescent plasma significantly reduces mortality. (Am J Pathol 2021, 191: 90-107; https://doi.org/10.1016/ j.ajpath.2020.10.008)
\end{abstract}

Coronavirus disease 2019 (COVID-19), caused by severe acute respiratory syndrome coronavirus 2 (SARS-CoV-2), has caused massive societal disruption and death globally. As of September 27, 2020, there have been $>33$ million COVID-19 cases, causing in excess of 1,000,000 deaths worldwide. ${ }^{1}$ The United States has many areas where rising case rates continue to threaten multiple populations. Few effective treatments exist (https://www.covid19treatmentguidelines.nih.gov, last accessed September 24, 2020), in spite of hundreds of ongoing registered clinical trials, including several phase 3 vaccine trials (https://www.nytimes.com/interactive/2020/ science/coronavirus-vaccine-tracker.html, required, last accessed September 24, 2020).

Supported by the Fondren Foundation (J.M.M.), Houston Methodist Hospital (J.M.M.), and the Houston Methodist Research Institute (J.M.M.).

Disclosures: E.S. is the local principal investigator for a clinical trial sponsored by Regeneron, assessing an investigational therapy for COVID-19. 
We and others have published safety and efficacy outcomes in patients transfused with COVID-19 convalescent plasma. ${ }^{2-4}$ Aggregated available evidence prompted the US Food and Drug Administration (FDA) in late August 2020 to grant Emergency Use Authorization for COVID-19 convalescent plasma therapy (https://www. fda.gov/media/141477/download, last accessed September $24,2020)$. In our previous study, interim analysis revealed that, relative to matched controls, patients transfused with convalescent plasma containing high-titer anti-spike protein receptor binding domain (RBD) IgG within 72 hours of hospital admission significantly reduced mortality at 28 days after transfusion. ${ }^{3}$

To further investigate these observations, and to address limitations inherent in an interim analysis, we herein present results from a 60-day follow-up of our entire cohort of 351 transfused patients. The data confirm our previous findings that transfusion of patients soon after hospital admission with high-titer anti-spike protein RBD IgG present in convalescent plasma significantly decreases mortality.

\section{Materials and Methods}

We analyzed data from patients cared for in all eight Houston Methodist hospitals from March 28, 2020, through September 14, 2020, with the approval of the Houston Methodist Research Institute ethics review board and with written informed consent of the patient or legally authorized representative. Details of the study, including inclusion and exclusion criteria, and criteria for the transfusion of multiple units have been described. ${ }^{3}$

\section{Convalescent Plasma Donors, Antibody Titer Assessment, and Donor Unit Selection}

Detailed protocols for convalescent plasma collection and anti-spike protein titer assessment have been described. ${ }^{3,5,6}$ COVID-19 convalescent plasma units were selected for transfusion on the basis of anti-spike ectodomain and RBD
IgG enzyme-linked immunosorbent assay (ELISA) titers available on donor units obtained from April 7, 2020, onward. We previously published that plasma with an antiRBD IgG titer of $\geq 1: 1350$ corresponds to an approximately $80 \%$ probability of a live virus in vitro neutralization titer of $\geq 1: 160{ }^{7}$ This titer is the value initially recommended by the FDA for transfusing COVID-19 patients. $^{8}$ To facilitate the need for increased donor unit assessment, we standardized our ELISA to four plasma dilutions: 1:50, 1:150, 1:450, and 1:1350. To select the highest titer unit available, ELISA results were ranked on the basis of highest titer and subsequently by highest OD at dilution 1:50. Patients were transfused with the ABOcompatible convalescent plasma unit with the highest titer and highest OD at dilution 1:50 available. Frozen serum samples were assessed retrospectively with the Ortho VITROS IgG assay (Ortho Clinical Diagnostics, Raritan, NJ), according to manufacturer's instructions.

\section{Statistical Analysis}

We analyzed patients who met a 60-day outcome, defined as having outcome data available 60 days after transfusion (cases) and 60 days after hospitalization (controls). Control patients enrolled in other clinical trials were excluded from the analysis. Patients discharged before day 60 were presumed to be on room air after discharge unless otherwise noted in the electronic medical record. Baseline characteristics for COVID-19 patients who met the 60-day outcome definition are shown in Supplemental Table S1.

We conducted a one-to-many nearest neighbor propensity score matching analysis without replacement using an initial ratio of case/control of 1:3 and caliper of $\leq 1$ between patients having plasma transfusion (cases) versus patients who did not have plasma transfusion (controls). The primary matching criteria included age (categorical, $<30,30$ to 39 , 40 to 49,50 to 59,60 to 69,70 to 79 , and $\geq 80$ years), sex, body mass index $\left(<30\right.$ or $\left.\geq 30 \mathrm{~kg} / \mathrm{m}^{2}\right)$, diabetes, hypertension, chronic pulmonary disease, chronic kidney disease,

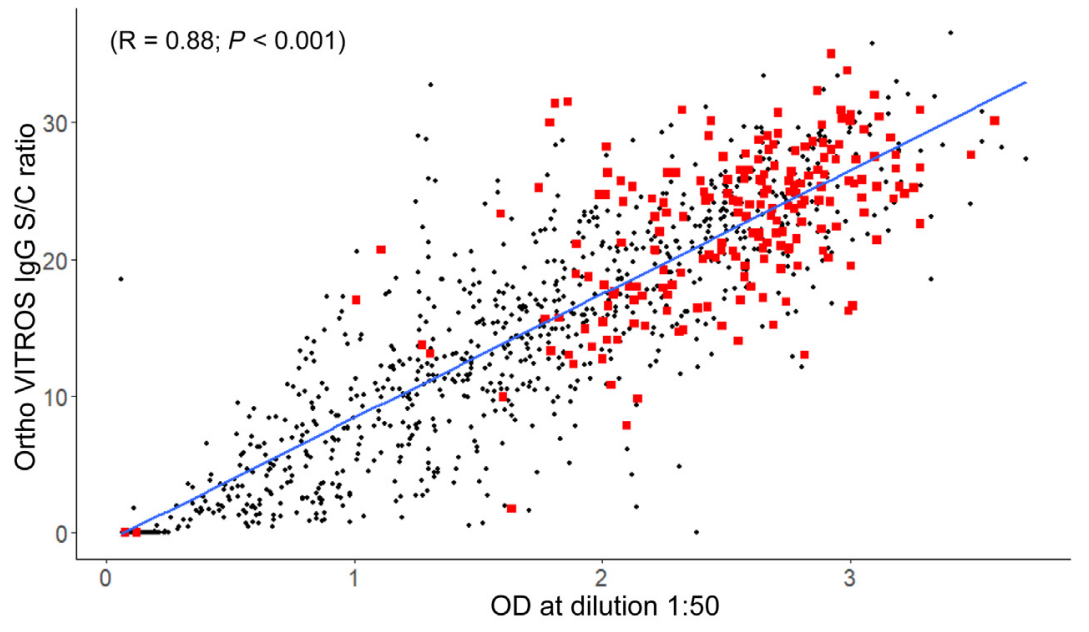

Figure 1 Ortho VITROS IgG signal/cutoff $(\mathrm{S} / \mathrm{C})$ ratio versus optical density (OD) at dilution 1:50 for serum samples for all convalescent plasma collections and for which parallel testing data were available through September 27, 2020. The blue line indicates the linear regression line of best fit. Positive linear correlation was significant $(\mathrm{R}=0.88 ; P<0.001)$. Red squares denote units transfused in the study. Black circles denote samples for all other units collected and not transfused during the study. Many of these units (black circles) were deferred because of the presence of donor human leukocyte antigen antibodies or positive donor severe acute respiratory syndrome coronavirus 2 nasopharyngeal swab at the time of donation. 


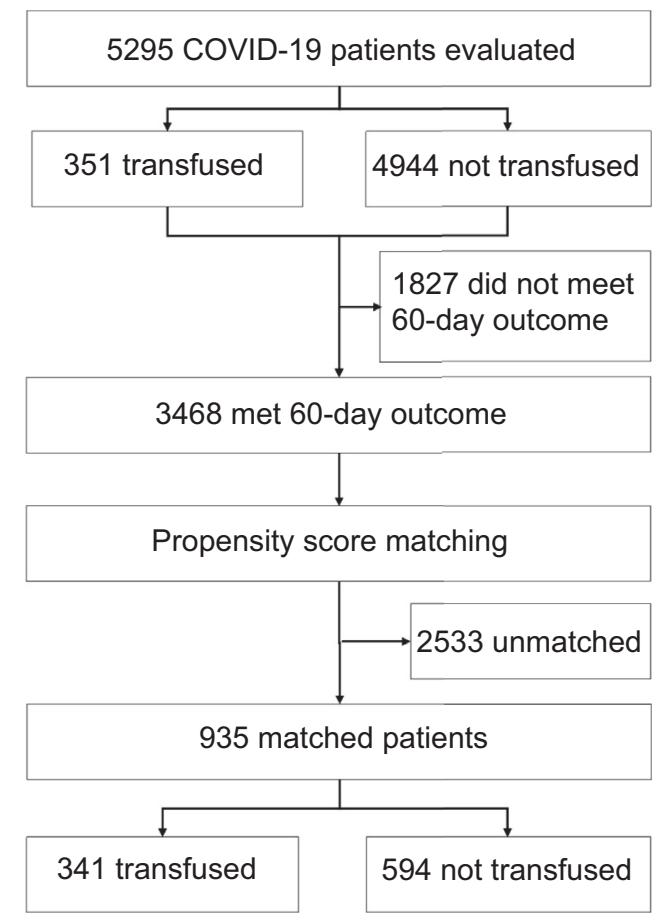

Figure 2 Flowchart of the study population. Propensity score matching was based on patient age (categorical, per 10 years); sex; body mass index (categorical, $<30$ or $\geq 30 \mathrm{~kg} / \mathrm{m}^{2}$ ); presence of diabetes, hypertension, chronic pulmonary disease, chronic kidney disease, hyperlipidemia, and/or coronary disease; baseline ventilation status within 48 hours of admission (room air, supplemental oxygen, and mechanical ventilation); and use of any steroid, azithromycin, hydroxychloroquine, remdesivir, ribavirin, and tocilizumab. After establishing the first propensity score-matched cohort and obtaining day 0 for controls, a second match was run between cases and controls based on the ventilation status at day 0. COVID-19, coronavirus disease 2019

hyperlipidemia, coronary disease, baseline ventilation requirement within 48 hours of admission, and use of any steroid, azithromycin, hydroxychloroquine, remdesivir, ribavirin, and tocilizumab. A secondary propensity score matching was conducted on the basis of the ventilation status at day 0 , defined as the day of transfusion for cases and the corresponding day in the hospitalization course for controls, using a case/control ratio of either $1: 2$ or $1: 1$ and caliper $\leq 1 .{ }^{9}$ Propensity score matching adjusts for the influences of potential confounding factors and minimizes bias in estimating outcome effect. ${ }^{10}$ The approach has a particular advantage in lieu of randomized controlled trials.

The primary outcome (mortality within 60 days after day 0 ) was displayed by Kaplan-Meier curves. Differences between groups were compared with the log-rank test. Cox proportional hazards modeling (with clustered sandwich estimator option for the matched cluster in the propensitymatched cohorts) was performed to determine the characteristics associated with the overall mortality within 28 and 60 days. Variables for the multivariable models were selected on the basis of potential clinical relevance and using Stata's (College Station, TX) Lasso technique with cross-validation. ${ }^{11,12}$ Receiver operating characteristic curve analysis with Youden index was used to identify the optimal time (in hours) from admission to transfusion of first unit that discriminates 60-day mortality in patients who received COVID-19 convalescent plasma. $^{13}$ Receiver operating characteristic analysis with Youden index allows for the determination of the optimal cut point for continuous variables, at which the combination of the sensitivity and specificity of the evaluated variable is maximized.

Generalized linear modeling and multinomial logistic regression with a cluster variance estimator were also used to evaluate several exploratory endpoints. The evaluated covariates included supplemental oxygen requirements (room air, low-flow oxygen delivery, high-flow oxygen delivery, noninvasive positive pressure ventilation, mechanical ventilation, extracorporeal membrane oxygenation, or death) at day 7 , day 14, day 28 , and day 60 after transfusion; clinical improvement relative to day 0 ; intensive care unit stay requirement; intensive care unit length of stay; mechanical ventilation requirement; length of mechanical ventilation requirement; length of supplemental oxygen requirement; and inflammatory marker levels (IL-6, C-reactive protein, ferritin, fibrinogen, and D-dimer) at day 7. Clinical improvement relative to day 0 was defined as a 1-point improvement in ordinal scale [1, discharged (alive); 2, hospitalized, not requiring supplemental oxygen but requiring ongoing medical care (for COVID-19 or otherwise); 3, hospitalized, requiring low-flow supplemental oxygen; 4 , hospitalized, on noninvasive ventilation or high-flow oxygen devices; 5 , hospitalized and on invasive mechanical ventilation or extracorporeal membrane oxygenation; and 6, death]. All analyses were performed with Stata version 16.1 (StataCorp LLC, College Station, TX) or the R Statistical Computing environment (http://www.R-project.org, last accessed September 24, 2020). $P \leq 0.05$ was considered significant.

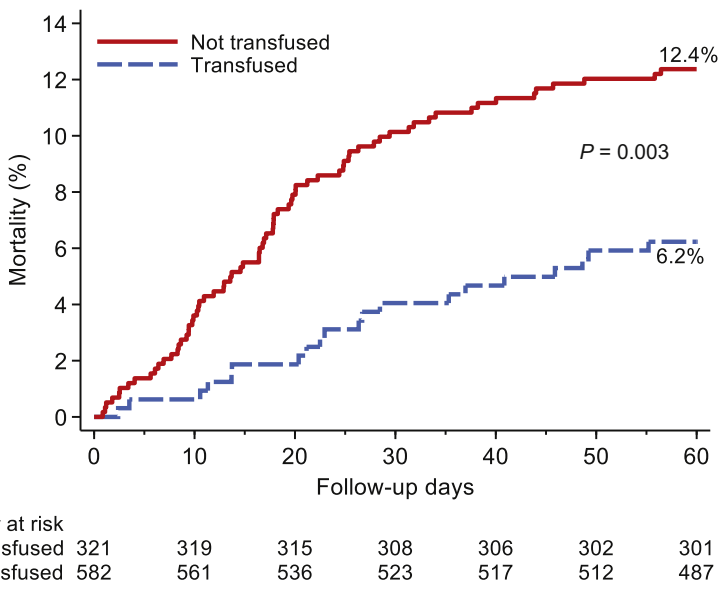

Figure 3 Kaplan-Meier curves for mortality within 60 days after day 0 for all patients who received plasma with an anti-receptor binding domain IgG titer $\geq 1: 1350$ regardless of time from admission (blue) propensity score matched to controls (red). 
A

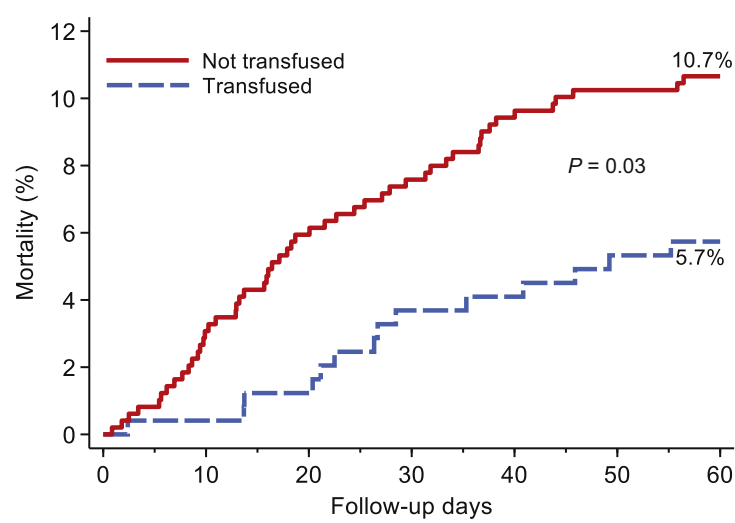

Number at risk

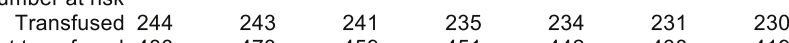
$\begin{array}{lllllll}\text { Not transfused } & 488 & 473 & 459 & 451 & 442 & 438\end{array}$

\section{C}

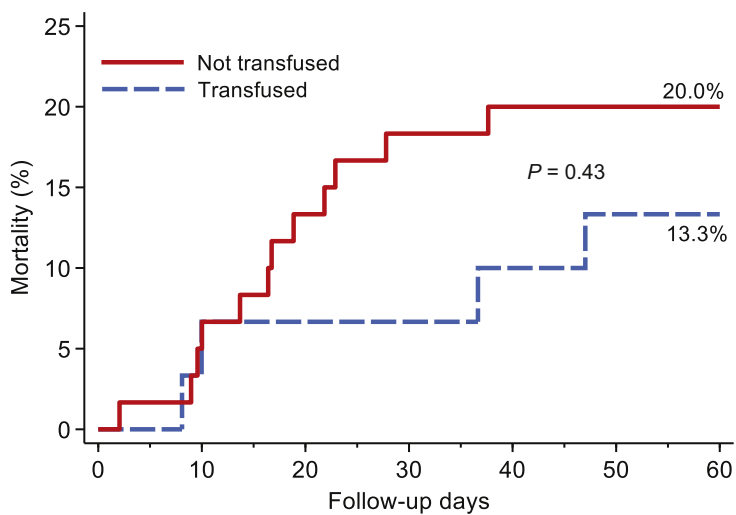

Number at risk

$\begin{array}{rlllllll}\text { Transfused } & 30 & 28 & 28 & 28 & 27 & 26 & 26 \\ & 57 & 52 & 49 & 48 & 48 & 48\end{array}$
B

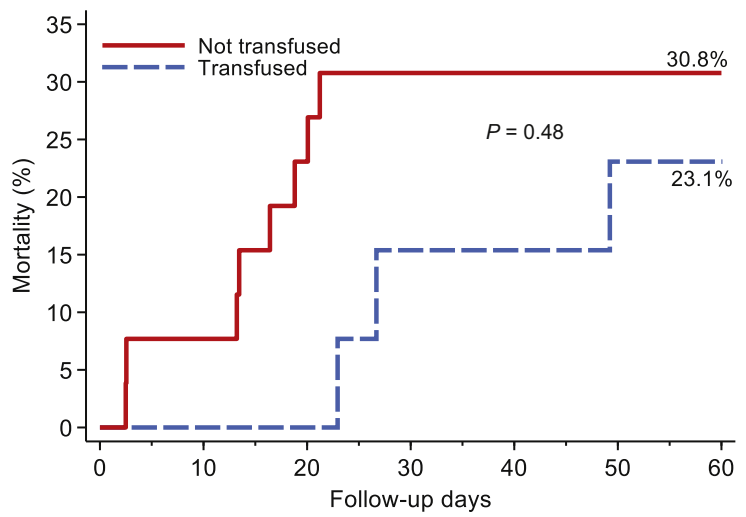

Number at risk

$\begin{array}{llllllll}\text { Transfused } & 13 & 13 & 13 & 11 & 11 & 10 & 10\end{array}$ $\begin{array}{lllllll}\text { Not transfused } & 26 & 24 & 20 & 18 & 18 & 18\end{array}$

D

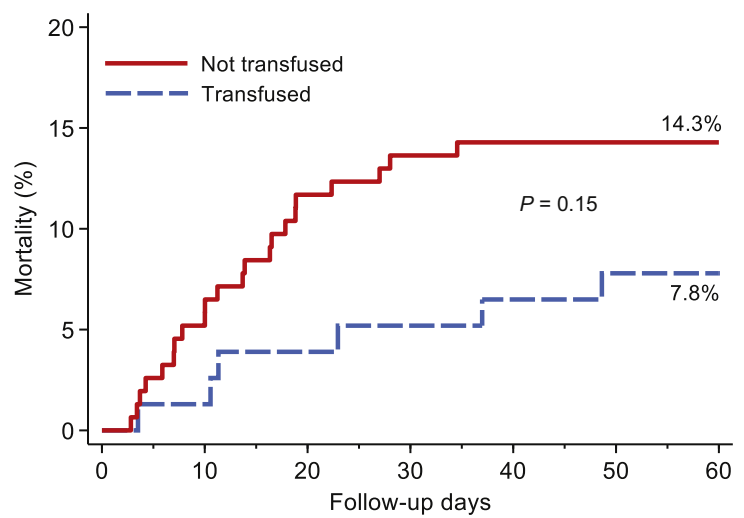

Number at risk

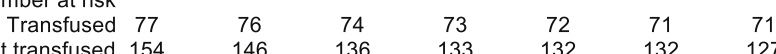

Figure 4 Kaplan-Meier curves for mortality within 60 days after day 0 for different cohorts of propensity score-matched patients and controls. A: Patients transfused with plasma with an anti-receptor binding domain (RBD) IgG titer $\geq 1: 1350$ and transfused within 72 hours of admission (blue) propensity score matched to control patients (red). B: Patients transfused with plasma with an anti-RBD IgG titer $\geq 1: 1350$ and intubated at day 0 (blue) propensity score matched to control patients intubated at day 0 (red). C: Patients transfused with plasma with an anti-RBD IgG titer $<1: 1350$ (blue) propensity score matched to control patients (red). D: Patients transfused with plasma with an anti-RBD IgG titer $\geq 1: 1350$ and transfused $>72$ hours after admission (blue) propensity score matched to control patients (red).

\section{Results}

\section{Study Population and Baseline Characteristics}

Of the 5297 hospitalized COVID-19 patients available for analysis, 353 were transfused with COVID-19 convalescent plasma. Two of the 353 patients received plasma without a titer assessment before transfusion and were excluded from the overall analysis, resulting in a cohort of 351 transfused evaluable patients. Relative to non-transfused patients, transfused patients were significantly younger, were predominantly male, were predominantly Hispanic, had a higher body mass index, had lower rates of comorbidities (specifically, chronic pulmonary disease, chronic kidney disease, hyperlipidemia, and coronary disease, but not hypertension and diabetes), had a higher requirement for supplemental oxygen, and had higher inflammatory biomarker concentrations. D-dimer was significantly lower in the transfused cohort at baseline by 0.2 fibrinogen equivalent units. Use of steroids, azithromycin, remdesivir, and tocilizumab was more common among the transfused cohort (Supplemental Table S1).

\section{Safety}

Among 351 transfused patients included in the study, 7 (2.0\%) had adverse events deemed related to plasma transfusion. Six events were classified as allergic transfusion reactions, five of which were mild and included only a transient rash. One patient developed transient worsening of shortness of breath that resolved with diphenhydramine. One case of possible transfusion-associated circulatory overload occurred with associated transient worsening of 
Table 1 Outcome Summary

\begin{tabular}{|c|c|c|c|c|c|}
\hline \multirow[b]{3}{*}{ Variable } & \multicolumn{5}{|c|}{ Propensity score matched, titer $\geq 1: 1350$} \\
\hline & \multirow{2}{*}{$\begin{array}{l}\text { Total } \\
(N=903)\end{array}$} & \multirow{2}{*}{$\begin{array}{l}\text { Not transfused } \\
(n=582)\end{array}$} & \multirow{2}{*}{$\frac{\text { Transfused }}{(n=321)}$} & \multirow{2}{*}{$\frac{\text { Point estimate }}{(95 \% \mathrm{CI})^{*}}$} & \multirow[b]{2}{*}{$P$ value } \\
\hline & & & & & \\
\hline Still admitted & $11(1.2)$ & $6(1.0)$ & $5(1.6)$ & 0.71 (0.19 to 2.56$)$ & 0.60 \\
\hline Discharge & $799(88.5)$ & $503(86.4)$ & $296(92.2)$ & (Base outcome) & \\
\hline Death & $93(10.3)$ & $73(12.5)$ & $20(6.2)$ & $2.15(1.30$ to 3.54$)$ & 0.003 \\
\hline Alive & $834(92.4)$ & $525(90.2)$ & $309(96.3)$ & $2.62(1.46$ to 4.70$)$ & 0.001 \\
\hline Deceased & $69(7.6)$ & $57(9.8)$ & $12(3.7)$ & & \\
\hline \multicolumn{6}{|l|}{$\begin{array}{l}\text { Overall mortality } \\
\text { within } 60 \text { days } \\
\text { after day } 0\end{array}$} \\
\hline \multicolumn{6}{|l|}{$\begin{array}{l}\text { Required ICU after } \\
\text { day } 0\end{array}$} \\
\hline No & $607(67.2)$ & $392(67.4)$ & $215(67.0)$ & $0.99(0.84$ to 1.16$)$ & 0.89 \\
\hline Yes & $296(32.8)$ & $190(32.6)$ & $106(33.0)$ & & \\
\hline $\begin{array}{l}\text { ICU length of stay } \\
\text { after day } 0 \text {, } \\
\text { mean } \pm S D \text {, days }\end{array}$ & $12.0 \pm 12.8$ & $11.6 \pm 12.3$ & $12.7 \pm 13.6$ & $-1.07(-4.01$ to 1.88$)$ & 0.48 \\
\hline \multicolumn{6}{|l|}{$\begin{array}{l}\text { Mechanical ventilation } \\
\text { requirement, } \\
\text { after day } 0\end{array}$} \\
\hline No & $752(83.3)$ & $477(82.0)$ & $275(85.7)$ & $1.26(0.97$ to 1.63$)$ & 0.08 \\
\hline Yes & $151(16.7)$ & $105(18.0)$ & $46(14.3)$ & & \\
\hline No & $77(8.5)$ & $55(9.5)$ & $22(6.9)$ & 0.99 (0.99 to 0.99$)$ & $<0.001$ \\
\hline Yes & $826(91.5)$ & $527(90.5)$ & $299(93.1)$ & & \\
\hline $\begin{array}{l}\text { Supplemental oxygen } \\
\text { time after day } 0 \text { (in } \\
\text { patients who } \\
\text { required } \\
\text { supplemental } \\
\text { oxygen), median } \\
\text { (IQR), days }\end{array}$ & $6.4 \pm 7.0$ & $6.5 \pm 7.1$ & $6.3 \pm 6.9$ & $0.23(-0.65$ to 1.12$)$ & 0.61 \\
\hline \multicolumn{6}{|l|}{$\begin{array}{l}\text { Ventilation status at } \\
\text { day } 0\end{array}$} \\
\hline Room air & $81(9.0)$ & $54(9.3)$ & $27(8.4)$ & (Base outcome) & \\
\hline Low flow & $549(60.8)$ & $353(60.7)$ & $196(61.1)$ & $0.90(0.55$ to 1.48$)$ & 0.68 \\
\hline High flow/NIPPV & $234(25.9)$ & $149(25.6)$ & $85(26.5)$ & $0.90(0.53$ to 1.54$)$ & 0.70 \\
\hline $\begin{array}{l}\text { Mechanical } \\
\text { ventilation }\end{array}$ & $36(4.0)$ & $24(4.1)$ & $12(3.7)$ & 0.87 (0.41 to 1.83$)$ & 0.70 \\
\hline ECMO & $3(0.3)$ & $2(0.3)$ & $1(0.3)$ & $0.52(0.07$ to 3.89$)$ & 0.52 \\
\hline Death & $0(0.0)$ & $0(0.0)$ & $0(0.0)$ & & \\
\hline \multicolumn{6}{|l|}{$\begin{array}{l}\text { Ventilation status at } \\
\text { day } 7\end{array}$} \\
\hline Room air & $532(58.9)$ & $339(58.2)$ & $193(60.1)$ & (Base outcome) & \\
\hline Low flow & $105(11.6)$ & $63(10.8)$ & $42(13.1)$ & $0.85(0.56$ to 1.31$)$ & 0.47 \\
\hline High flow/NIPPV & $151(16.7)$ & $102(17.5)$ & $49(15.3)$ & 1.19 (0.85 to 1.65$)$ & 0.31 \\
\hline
\end{tabular}


Table 1 (continued)

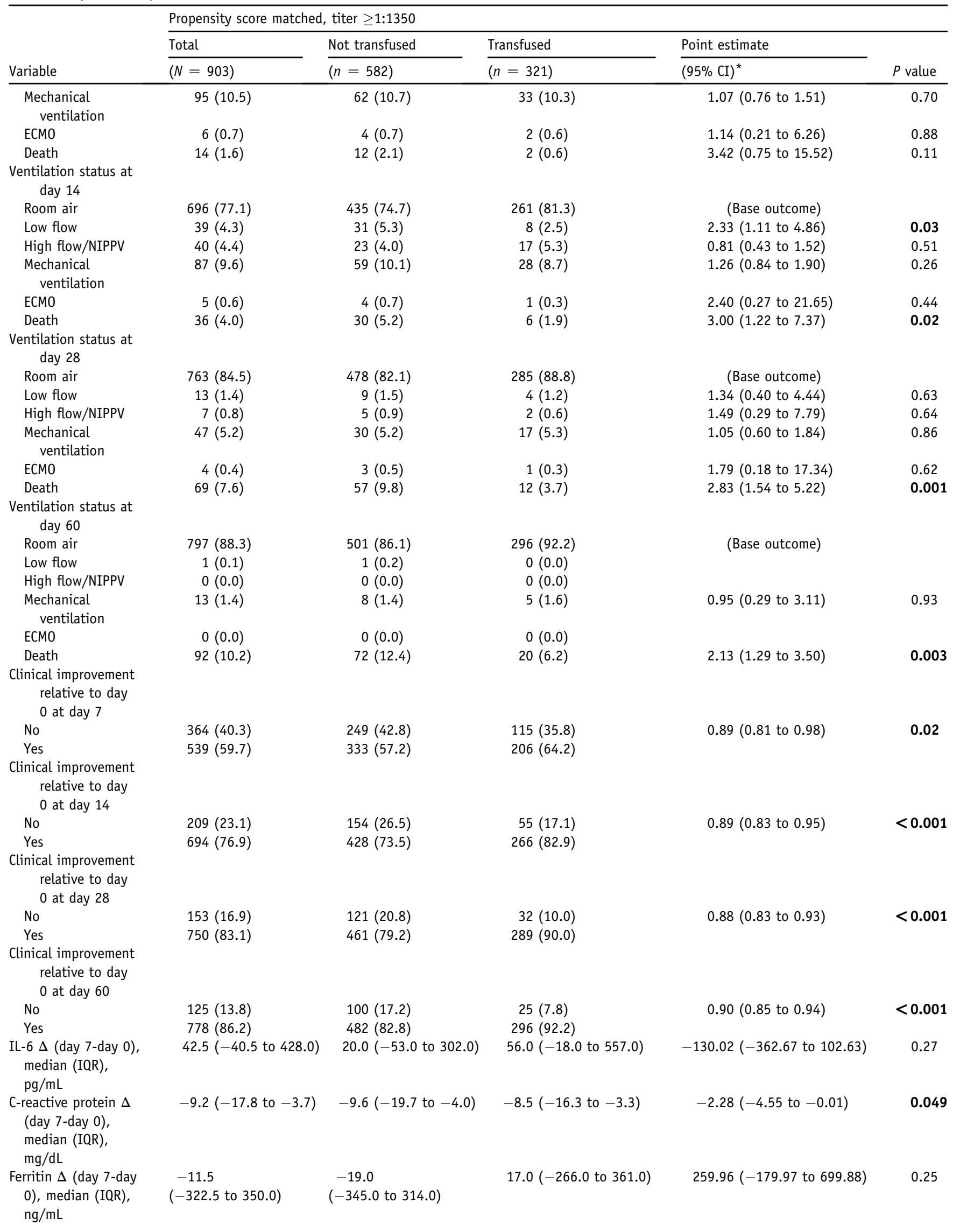


Table 1 (continued)

\begin{tabular}{|c|c|c|c|c|c|}
\hline \multirow[b]{3}{*}{ Variable } & \multicolumn{5}{|c|}{ Propensity score matched, titer $\geq 1: 1350$} \\
\hline & Total & Not transfused & Transfused & Point estimate & \\
\hline & $(N=903)$ & $(n=582)$ & $(n=321)$ & $(95 \% \mathrm{CI})^{*}$ & $P$ value \\
\hline $\begin{array}{l}\text { Fibrinogen } \Delta \text { (day } 7 \text { - } \\
\text { day } 0), \text { median } \\
(\mathrm{IQR}), \mathrm{mg} / \mathrm{dL}\end{array}$ & $\begin{array}{l}-164.0 \\
(-342.0 \text { to }-36.0)\end{array}$ & $\begin{array}{l}-191.0 \\
(-342.0 \text { to }-57.0)\end{array}$ & $-136.5(-339.0$ to -31.0$)$ & $-55.08(-125.30$ to 15.13$)$ & 0.12 \\
\hline $\begin{array}{l}\text { D-dimer } \Delta \text { (day 7-day } \\
\text { 0), median (IQR), } \\
\mu \mathrm{g} / \mathrm{mL} \text { FEU }\end{array}$ & $0.2(-0.3$ to 1.5$)$ & $0.1(-0.4$ to 1.3$)$ & $0.4(-0.2$ to 1.6$)$ & $-0.80(-1.89$ to 0.30$)$ & 0.15 \\
\hline
\end{tabular}

Values are expressed as median (IQR) for continuous variables and $n(\%)$ for categorical variables. Bolded values are statistically significant $(P<0.05)$.

*Point estimate obtained from generalized linear models (for binary and continuous dependent variables) or multinomial logistic regression (for categorical dependent variables), which is risk ratio of outcome in non-transfusion versus transfusion (if categorical outcomes) or coefficient of outcome in nontransfusion versus transfusion (if continuous outcomes).

ECMO, extracorporeal membrane oxygenation; FEU, fibrinogen equivalent unit; ICU, intensive care unit; IQR, interquartile range; NIPPV, noninvasive positive pressure ventilation.

dyspnea that improved with furosemide. These two events were deemed to be significant adverse events. Thus, among the 351 transfused study patients, $2(0.6 \%)$ significant adverse events were deemed related to plasma transfusion.

Factors Associated with a Higher Risk of Death in all Hospitalized COVID-19 Patients

Univariate and multivariate Cox proportional hazards modeling, assessing factors associated with a higher risk of death within 60 days after transfusion day 0 were performed for all COVID-19 patients admitted to the eight Houston Methodist hospitals during the study period for whom data were available (Supplemental Tables S2 and S3). Factors associated with a higher risk of death in the multivariate analysis included age, male sex, diabetes, chronic kidney disease, worst ventilation status within 48 hours of admission, and/or administration of any steroids or tocilizumab. ABO blood type, race, or ethnicity were not associated with higher risk of death in the multivariate analysis. More important, the covariates that had a significant association with risk of death were included in the propensity score matching algorithm. Baseline inflammatory concentrations in the multivariate analysis and in the propensity score matching algorithm were not included because of the high proportion of missing data.

\section{COVID-19 Convalescent Plasma and Retrospective Analysis of Ortho VITROS IgG Test Data}

Most transfused patients $(278 / 351 ; 79 \%)$ received one approximately 300-mL unit of COVID-19 convalescent plasma. Majority of patients received an initial or sole unit of convalescent plasma with anti-RBD IgG titer of $\geq 1: 1350$ (321/351; 91\%); 24 patients received an initial or sole unit of convalescent plasma with an anti-RBD IgG titer $>1: 150$ but $<1: 1350$; 6 patients received an initial or sole unit of convalescent plasma with anti-RBD IgG titer of $<1: 150$. Of the patients who received a second unit of convalescent plasma, $71(71 / 75 ; 95 \%)$ received it with an anti-RBD IgG titer $\geq 1: 1350$, and $4(4 / 75 ; 5 \%)$ patients received it with an anti-RBD IgG titer $>1: 150$ but $<1: 1350$.

The FDA issued an Emergency Use Authorization for convalescent plasma transfusion of COVID-19 patients on August 23, 2020. The agency's guidance is to use convalescent plasma units with a signal/cutoff (S/C) level of $>12$, as defined by the Ortho VITROS IgG test (https://www.fda. gov/media/141477/download, last accessed September 24, 2020). For 278 of the 351 (79\%) initial plasma units transfused, a sample was available for retrospective assessment of anti-SARS-CoV-2 IgG titer by the Ortho VITROS IgG test. The median $\operatorname{IgG} \mathrm{S} / \mathrm{C}$ ratio was 24 . 0 (range, 0.01 to 35), and seven units (3\%) had a corresponding $\mathrm{S} / \mathrm{C}$ ratio of $<12$. In addition, there was a strong positive correlation between the ELISA anti-RBD IgG OD at dilution 1:50 and the Ortho VITROS IgG test for 1142 samples with parallel assessment $(\mathrm{R}=0.88$; $P<0.001)$. The distribution of Ortho VITROS IgG S/C ratios and anti-RBD IgG ELISA OD for transfused plasma units confirms that high anti-spike protein IgG titer units were being given to the enrolled COVID-19 patients (Figure 1).

\section{Outcomes}

Propensity score matching yielded a study population of 341 transfused patients and 594 matched controls, which were balanced across all matching criteria (Figure 2 and Supplemental Table S4). Kaplan-Meier curves showed significantly decreased mortality within 60 days after day 0 in the transfused cohort relative to propensity score-matched controls $(P=0.02)$ (data not shown). Statistical significance increased to $P=0.003$ when the matching algorithm and analysis were restricted to patients transfused with plasma with an anti-RBD IgG titer of $\geq 1: 1350 \quad$ (Figure 3). Mortality was not significantly different within 60 days after day 0 between cases and controls in patients who were intubated at day 0 or in 
patients who were transfused $>72$ hours after admission, even when the analysis was restricted to patients who received plasma with an anti-RBD IgG titer of $\geq 1: 1350$. No significant difference was observed in mortality between cases and controls when the analysis was restricted to patients who received plasma with an anti-RBD IgG titer of $<1: 1350$. In contrast, mortality was significantly decreased in patients who received plasma with an anti-RBD IgG titer of $\geq 1: 1350$ within 72 hours of admission (Figure 4). Point estimates of the outcomes for analysis restricted to transfusion of high-titer plasma confirm these findings (Table 1).

Consistent with these observations, the unadjusted hazard ratio (HR) and adjusted HR (aHR) in the univariate and multivariate Cox proportional hazards models for mortality within 60 days were significant for analysis restricted to patients who received plasma with an anti-RBD IgG titer of $\geq 1: 1350$ (Table 2). Because of small sample sizes, multivariate analysis could not be performed for patients who received plasma with a titer $\geq 1: 1350$ and were intubated at day 0 , or who were transfused $>72$ hours after hospitalization. In these two cohorts, the unadjusted HR in univariate analyses for mortality within 60 days after day 0 was not significant $[\mathrm{HR}=1.61$ for controls $(P=0.44)$ and HR $=1.93$ for controls $(P=0.16)$, respectively]. Similarly, the unadjusted HR for mortality within 60 days in the analysis restricted to patients who received plasma with a titer $<1: 1350$ was also not significant $(\mathrm{HR}=1.57$ for controls; $P=0.36$ ). However, the unadjusted HR for mortality within 60 days was significant $(\mathrm{HR}=1.93$ for controls; $P=0.02$ ) when the analysis was restricted to patients who received plasma with a titer $\geq 1: 1350$ within 72 hours of hospital admission. For this cohort, the aHR for mortality within 60 days was significant when assessed for a 28-day outcome (aHR $=2.09$ for controls; $P=0.047)$ and approached significance when assessed for a 60-day outcome (aHR $=1.82$ for controls; $P=0.051$ ).

We sought to identify the optimal window after hospitalization within which transfusion of convalescent plasma was most useful with respect to altering mortality. Receiver operating characteristic curve analysis with Youden index revealed an optimal cut point of transfusion within 44 hours of hospital admission for discriminating mortality within 60 days after transfusion in all patients transfused with COVID-19 convalescent plasma (Figure 5A). The analysis identified the same cut point when restricted to patients transfused with convalescent plasma with an anti-RBD IgG titer $\geq 1: 1350$. Therefore, we performed the propensity score-matched analysis using this cut point as a restrictor. Cohorts were balanced across all matching criteria (data not shown). The resulting Kaplan-Meier curves showed significantly decreased mortality within 60 days after day 0 in the cohort transfused with convalescent plasma with an antiRBD IgG $\geq 1: 1350$ within 44 hours of admission relative to propensity score-matched controls $(P=0.004)$ (Figure 5B). Point estimates of the outcomes for the analysis restricted to transfusion of high-titer convalescent plasma within 44 hours confirm these findings (Table 3). Univariate Cox regression in this cohort revealed a significant unadjusted HR for mortality within 60 days $(\mathrm{HR}=3.26$ for controls; $P=0.01$ ). Likewise, multivariate Cox regression showed a significant aHR for mortality within 28 days $(\mathrm{aHR}=2.63$ for controls; $P=0.04)$ and within 60 days after day $0($ aHR $=2.90$ for controls; $P=0.02$ ) (Table 4$)$.

\section{Discussion}

Transfusion of convalescent plasma has emerged in the last 6 months as a promising therapy for COVID-19 patients and has been granted Emergency Use Authorization for hospitalized patients by the FDA. Because of the logistical challenges of planning and executing a study during a rapidly changing pandemic involving complex medical patients, the results of few completed controlled studies assessing convalescent plasma efficacy have been published. Herein, we provide an analysis of a propensity score-matched study from a large cohort of hospitalized COVID-19 patients who were transfused in one health care system with high-titer convalescent plasma qualified in one laboratory. In the aggregate, the data confirm and extend findings from our interim analysis suggesting that transfusion of convalescent plasma with high-titer anti-RBD IgG is safe and significantly decreases COVID-19 mortality. ${ }^{3}$ Transfusion later in hospitalization or later in the disease course (eg, after intubation) had no significant benefit on mortality, regardless of plasma titer. Several lines of evidence support our findings, including survival analyses of specific cohorts of transfused patients relative to matched controls, point estimates from the generalized linear model and multinomial logistic regression, and univariate and multivariate analyses.

The current analysis addressed several limitations identified in our interim analysis. ${ }^{3}$ First, the patient sample size is almost three times as large as that included in our interim analysis. Second, we included additional covariates in the propensity score matching algorithm, including relevant concomitant medications (any steroid, azithromycin, hydroxychloroquine, remdesivir, ribavirin, and tocilizumab). More important, factors identified as having a significant aHR for mortality for all hospitalized COVID-19 patients were included in the propensity match. Third, because a large proportion of deaths occurred after 28 days post-day 0 , we assessed a 60 -day outcome. Fourth, control patients enrolled in other clinical trials involving alternative experimental therapies were excluded. Fifth, when possible, we performed multivariate analyses assessing factors associated with mortality within 60 days. Finally, we used receiver operating characteristic analysis with Youden index to identify the optimal cut point at which transfusion of convalescent plasma is most useful with respect to altering mortality. 
Table 2 Univariate and Multivariate Cox Regression, Overall Mortality within 28 and 60 Days, for Controls Matched to Cases Who Received Plasma with Titer $\geq 1: 1350$

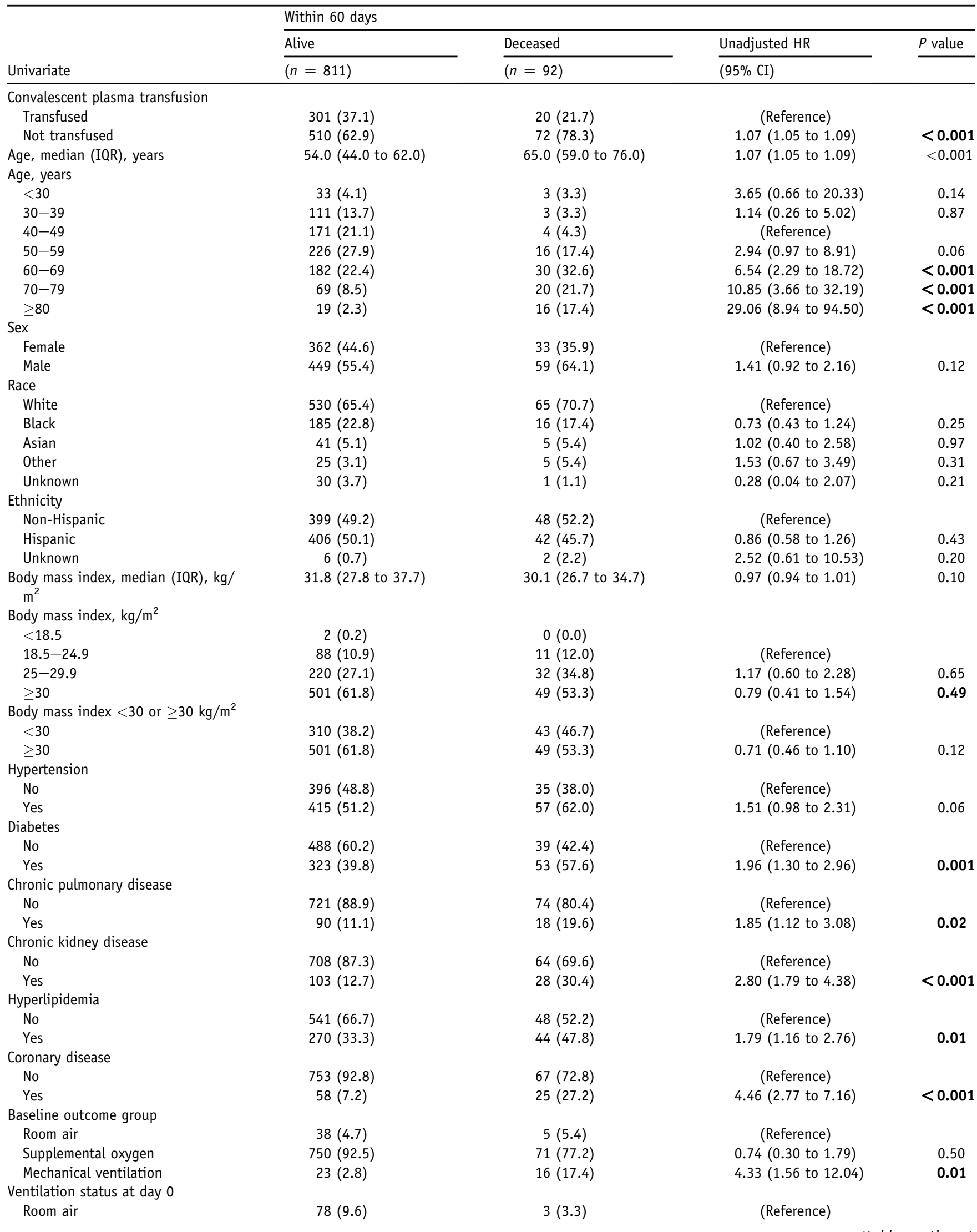


Table 2 (continued)

\begin{tabular}{|c|c|c|c|c|}
\hline \multirow[b]{3}{*}{ Univariate } & \multicolumn{4}{|l|}{ Within 60 days } \\
\hline & \multirow{2}{*}{$\frac{\text { Alive }}{(n=811)}$} & \multirow{2}{*}{$\frac{\text { Deceased }}{(n=92)}$} & \multirow{2}{*}{$\frac{\text { Unadjusted HR }}{(95 \% \mathrm{CI})}$} & \multirow[t]{2}{*}{$P$ value } \\
\hline & & & & \\
\hline High flow/NIPPV & $194(23.9)$ & $40(43.5)$ & $4.99(1.63$ to 15.25$)$ & 0.01 \\
\hline Mechanical ventilation & $20(2.5)$ & $16(17.4)$ & 15.69 (4.74 to 52.02$)$ & $<0.001$ \\
\hline ECMO & $3(0.4)$ & $0(0.0)$ & & \\
\hline B & $93(14.0)$ & $9(10.6)$ & $0.74(0.36$ to 1.52$)$ & 0.42 \\
\hline$A B$ & $13(2.0)$ & $3(3.5)$ & $1.59(0.52$ to 4.84$)$ & 0.42 \\
\hline 0 & $356(53.5)$ & $48(56.5)$ & (Reference) & \\
\hline \multicolumn{5}{|l|}{ Rh blood group } \\
\hline Negative & $54(8.1)$ & $11(12.9)$ & (Reference) & \\
\hline Positive & $612(91.9)$ & $74(87.1)$ & $0.62(0.34$ to 1.15$)$ & 0.13 \\
\hline $\begin{array}{l}\text { C-reactive protein at baseline, } \\
\text { median (IQR), mg/dL }(n=725)\end{array}$ & 9.7 (5.3 to 16.4$)$ & $10.2(6.2$ to 15.2$)$ & 0.99 (0.97 to 1.02$)$ & 0.65 \\
\hline $\begin{array}{l}\text { C-reactive protein } \Delta \text { (day 7-baseline), } \\
\text { median (IQR), } \mathrm{mg} / \mathrm{dL}(n=403)\end{array}$ & $-9.5(-18.3$ to -3.6$)$ & $-8.0(-14.4$ to -4.3$)$ & 1.01 (0.99 to 1.03$)$ & 0.30 \\
\hline $\begin{array}{l}\text { Ferritin at baseline, median (IQR), } \\
\mathrm{ng} / \mathrm{mL}(n=726)\end{array}$ & 809.5 (427.0 to 1565.0$)$ & 1160.5 (543.5 to 1896.0$)$ & $1.00(1.00$ to 1.00$)$ & 0.052 \\
\hline $\begin{array}{l}\text { Ferritin } \Delta \text { (day 7-baseline), median } \\
\quad(\mathrm{IQR}), \mathrm{ng} / \mathrm{mL}(n=396)\end{array}$ & $-20.5(-351.0$ to 308.0$)$ & $141.5(-272.0$ to 591.0$)$ & $1.0002(1.00$ to 1.0003$)$ & 0.03 \\
\hline $\begin{array}{l}\text { Fibrinogen at baseline, median (IQR), } \\
\mathrm{mg} / \mathrm{dL}(n=534)\end{array}$ & $658.0(562.0$ to 749.0$)$ & $617.0(526.0$ to 720.0$)$ & $0.99(0.99$ to 1.00$)$ & 0.01 \\
\hline $\begin{array}{l}\text { Fibrinogen } \Delta \text { (day 7-baseline), } \\
\quad \text { median (IQR), } \mathrm{mg} / \mathrm{dL}(n=155)\end{array}$ & $-178.0(-347.5$ to -48.5$)$ & $-121.0(-246.0$ to 49.0$)$ & $1.00(1.00$ to 1.00$)$ & 0.37 \\
\hline Prednisone & $109(13.4)$ & $23(25.0)$ & $1.96(1.26$ to 3.04$)$ & 0.00 \\
\hline Azithromycin & $596(73.5)$ & $68(73.9)$ & $1.01(0.63$ to 1.60$)$ & 0.98 \\
\hline Hydroxychloroquine & $80(9.9)$ & $12(13.0)$ & $1.37(0.77$ to 2.42$)$ & 0.28 \\
\hline Lopinavir/ritonavir & $7(0.9)$ & $2(2.2)$ & $2.32(0.57$ to 9.46$)$ & 0.24 \\
\hline Remdesivir & $306(37.7)$ & $34(37.0)$ & 0.95 (0.61 to 1.49$)$ & 0.84 \\
\hline Ribavirin & $27(3.3)$ & $4(4.3)$ & 1.33 (0.48 to 3.66$)$ & 0.58 \\
\hline \multirow[t]{3}{*}{ Tocilizumab } & $358(44.1)$ & $73(79.3)$ & $4.49(2.70$ to 7.48$)$ & $<0.001$ \\
\hline & Within 28 days & & Within 60 days & \\
\hline & Adjusted HR & & Adjusted HR & \\
\hline Multivariate & $(95 \% \mathrm{CI})$ & $P$ value & $(95 \% \mathrm{CI})$ & $P$ value \\
\hline \multicolumn{5}{|l|}{ Convalescent plasma transfusion } \\
\hline Transfused & (Reference) & & (Reference) & \\
\hline Not transfused & 1.94 (1.05 to 3.58$)$ & 0.04 & 1.64 (1.00 to 2.69$)$ & 0.049 \\
\hline Age, years & 1.06 (1.04 to 1.09$)$ & $<0.001$ & 1.09 (1.05 to 1.13$)$ & $<0.001$ \\
\hline Diabetes & 1.69 (1.01 to 2.84$)$ & 0.046 & 1.57 (1.02 to 2.43$)$ & 0.04 \\
\hline Chronic kidney disease & $1.44(0.79$ to 2.60$)$ & 0.23 & $1.41(0.83$ to 2.40$)$ & 0.20 \\
\hline \multicolumn{5}{|l|}{ Ventilation status at day 0} \\
\hline Room air & (Reference) & & & \\
\hline Low flow & $3.42(0.51$ to 23.12$)$ & 0.21 & $1.46(0.49$ to 4.34$)$ & 0.50 \\
\hline High flow/NIPPV & 5.14 (0.75 to 35.13$)$ & 0.10 & 2.71 (0.96 to 7.64$)$ & 0.06 \\
\hline Mechanical ventilation & 12.99 (1.80 to 93.62$)$ & 0.01 & $5.68(1.91$ to 16.90$)$ & 0.002 \\
\hline
\end{tabular}


Table 2 (continued)

\begin{tabular}{|c|c|c|c|c|}
\hline \multirow[b]{3}{*}{ Multivariate } & \multicolumn{2}{|l|}{ Within 28 days } & \multicolumn{2}{|l|}{ Within 60 days } \\
\hline & Adjusted HR & & Adjusted HR & \\
\hline & $(95 \% \mathrm{CI})$ & $P$ value & $(95 \% \mathrm{CI})$ & $P$ value \\
\hline \multicolumn{5}{|l|}{ ECMO } \\
\hline Any steroids & 1.11 (1.03 to 1.21$)$ & 0.01 & 1.06 (1.00 to 1.13$)$ & 0.06 \\
\hline Tocilizumab & $1.06(1.01$ to 1.11$)$ & 0.01 & 1.04 (1.01 to 1.06$)$ & 0.01 \\
\hline C-statistic & 0.87 & & 0.81 & \\
\hline
\end{tabular}

Values are expressed as median (IQR) for continuous variables and $n(\%)$ for categorical variables. Bolded values are statistically significant $(P<0.05)$. Steroids and tocilizumab were treated as time-varying covariates in the multivariate model.

ECM0, extracorporeal membrane oxygenation; FEU, fibrinogen equivalent unit; HR, hazard ratio; IQR, interquartile range; NIPPV, noninvasive positive pressure ventilation.

Our results bear on other recent studies treating patients with convalescent plasma. ${ }^{4,9,14-17}$ For example, a recent fixed-effect meta-analysis model assessing 12 controlled studies of COVID-19 convalescent plasma found that the aggregate mortality rate of transfused COVID-19 patients was significantly lower than that of non-transfused patients. ${ }^{4}$ Results from three randomized controlled studies and one large observational study have recently been published. ${ }^{2,18-20}$ The PLAsma Convalescent InDia (PLACID) trial found that convalescent plasma was not associated with significantly reduced mortality or progression to severe disease. ${ }^{18}$ However, resolution of shortness of breath, fatigue, and negative conversion of SARS-CoV-2 viral RNA at day 7 was higher in the transfused study arm. The authors acknowledged several limitations of their study. For example, the proportion of patients with comorbidities, especially diabetes, was higher in the transfused study arm. More important, most of the convalescent plasma donors were young with mild disease and the median titer of

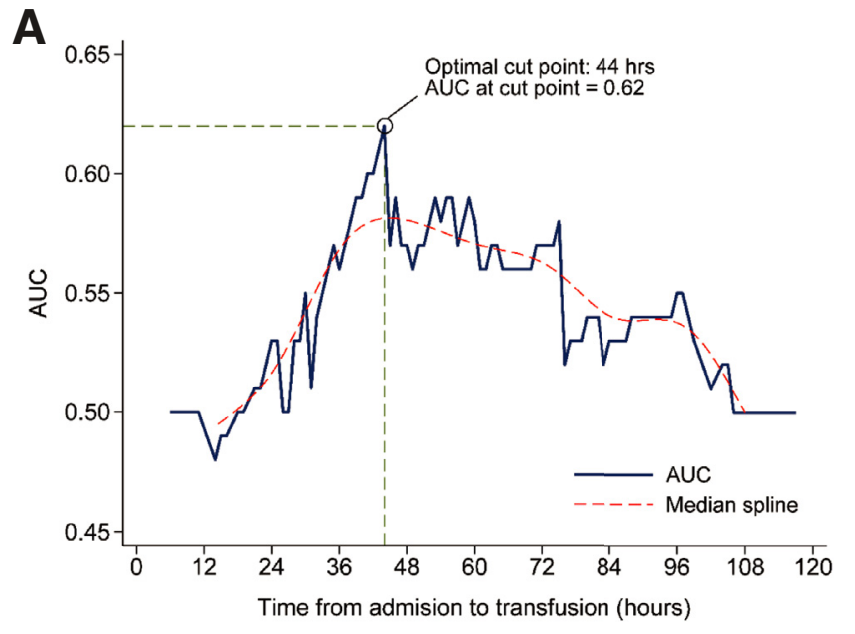

neutralizing antibody was $1: 40$, a value considerably lower than the FDA-recommended neutralizing antibody titer of 1:160. In addition, neutralizing antibody titers were not determined before transfusion, which means the highest titer units were not used for transfusion. Similar results were reported for a randomized controlled trial conducted in Chile in which neutralizing antibody titers in donor plasma were not determined before transfusion. ${ }^{20}$ In contrast, interim analysis of a randomized controlled trial from Spain with 81 randomized patients reported that no patients progressed to mechanical ventilation or death among the 38 patients receiving convalescent plasma (0\%), whereas 6 of 43 patients $(14 \%)$ in the control arm did. ${ }^{19}$ Mortality rates were $0 \%$ versus $9.3 \%$ at days 15 and 29 for the active and control groups, respectively. All transfused convalescent plasma units had neutralizing antibodies with a titer $>1: 80$ with a median titer of 1:292. Unfortunately, the trial was stopped after the first interim analysis because of decreased recruitment related to better control of the pandemic. In

B

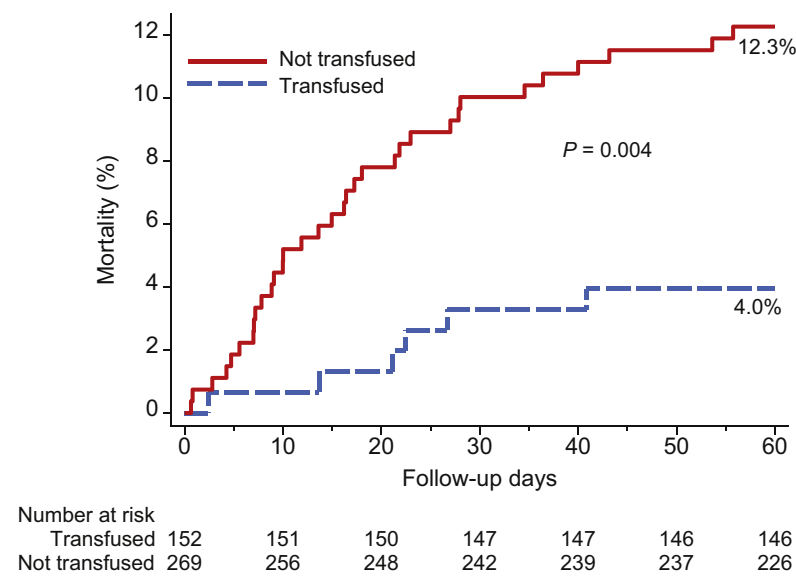

Figure 5 A: Receiver operating characteristic curve with Youden index analysis for mortality within 60 days shown for all patients transfused with coronavirus disease 2019 convalescent plasma. Optimal cut point identified as 44 hours with an area under the curve (AUC) of 0.62 . Youden index was 0.23 with SEM of 0.0926 . Sensitivity at cut point was 0.75 with a specificity of 0.48 . B: Kaplan-Meier curves for mortality within 60 days after day 0 for patients transfused with plasma with an anti-receptor binding domain IgG titer $\geq 1: 1350$ within 44 hours after admission (blue) propensity score matched to control patients (red). 
contrast to several of the studies cited above, we methodically selected units for transfusion based on the ELISA data identifying the highest level of $\operatorname{IgG}$ antibody directed against spike ectodomain and RBD. We transfused compatible donor units determined to have the highest antibody titer available, an approach confirmed by our retrospective assessment of anti-SARS-CoV-2 IgG by the Ortho VITROS assay (Figure 1). Thus, the vast majority of our patients were transfused with convalescent plasma units with high-titer anti-spike protein IgG. We think it reasonable to speculate that this strategy contributed to differences in outcomes observed between our study and several others that did not transfuse patients with plasma units specifically chosen to have high IgG antibody levels against spike protein. Overall, the results from various published studies highlight the difficulty in drawing definitive conclusions for convalescent plasma efficacy from multiple studies with variable design, a problem that can extend to and thereby hobble randomized controlled trials with different study designs.

Substantial efforts to collect, use, and study COVID-19 convalescent plasma continue worldwide. Our study has several implications for these efforts. The data presented herein may inform the design and conduct of ongoing or future studies. For example, we conclude that transfusing plasma units with low or no antibody titer against spike protein is unlikely to be beneficial. Our data support the concept that identification of units containing high antibody titer by either a viral neutralization assay or a surrogate thereof before transfusion is essential, regardless of the type of trial being conducted. COVID-19 convalescent plasma is now being administered widely in the United States under an Emergency Use Authorization, with an Ortho VITROS IgG cutoff of $>12$ required by the FDA for the designation of a high-titer unit. In our study, we prospectively selected units based on anti-RBD IgG ELISA data. Assessment of transfused units by the Ortho VITROS assay was done retrospectively. The relative lack of data from an adequate number of our patients transfused with convalescent plasma units near or below the S/C cutoff of 12 precludes evaluation of this cutoff value with respect to outcome. However, we conclude that prospective selection and transfusion of high-titer units likely contributed to the significantly decreased mortality observed. In addition, transfusing soon after hospitalization will be more beneficial than the alternative. Similarly, transfusion in patients who have progressed to the need for mechanical ventilation or otherwise have further deteriorated clinically likely confers no clear benefit. These findings support the notion that virus neutralizing antibodies present in COVID-19 convalescent plasma impart therapeutic benefit when patients are in the relatively early viral infection/replication phase of COVID19 disease, but not after patients have progressed to manifest disease mechanisms, such as a pathogenic severe inflammatory host response. ${ }^{21,22}$ Prioritizing studies targeted toward early disease patients is, therefore, important. Our finding that a large proportion of deaths in COVID-19 patients occur after day 28 may also have implications for study design, as findings at day 28 may not apply over a longer follow-up period.

Our study has several limitations. First, it is a propensity score-matched study rather than a randomized controlled trial. Although we made every effort to control for all important covariates, potentially relevant covariates may have been omitted unintentionally from the matching algorithm. Second, the background standard of care for COVID-19 has evolved with the emergence of new data. Thus, we may not have completely addressed the potential for variations over time in background standard of care and period effect as sources of confounding in our data set. Third, there was heterogeneity in the transfusion of two units versus one based on inventory limitations early in the study and on patient enrollment in other trials that specifically excluded redosing of convalescent plasma. Fourth, our analysis was based on patient data available in the electronic medical record. Fifth, we note that the results reflect the experience of one system of eight hospitals in the Houston metropolitan region that has a fairly uniform approach to COVID-19 patient care. Our findings may not apply to all hospitalized COVID-19 patients because of interinstitutional and/or regional heterogeneity in medical care. Sixth, baseline inflammatory marker measurements were not included in the matching algorithm because of the high proportion of missing data points. Our study approach facilitated rapid assessment of safety and efficacy of high-titer anti-SARS-CoV-2 convalescent plasma transfusion during early phases of a rapidly evolving pandemic with uncertain trajectory. The data presented herein may help to inform the science and logistics of ongoing and future studies that address the use of convalescent plasma for other emerging and rapidly disseminating infectious diseases.

To summarize, this propensity score-matched analysis of a large patient cohort confirms and extends our previous findings and suggests that transfusion of convalescent plasma containing high-titer anti-RBD IgG early in hospitalization reduces mortality in COVID-19 patients.

\section{Acknowledgments}

We thank all volunteer plasma donors for their time, donations, and solidarity; Katharine G. Dlouhy, Curt Hampton, and their team of coordinators and recruiters for their efforts; Monisha Dey and Cheryl Chavez-East for efficiently managing the donor center; Kate Cody, Sayali Kelkar, Belimat Askary, and the clinical analytics team for assistance with data acquisition and management; Drs. Jessica Thomas and Zejuan Li and Erika Walker, the molecular technologists, and the many labor pool volunteers in the Molecular Diagnostics Laboratory for dedication to patient 
Table 3 Outcome Summary, Propensity Score Matched, Transfused with Plasma with Titer $\geq 1: 1350$ within 44 Hours of Admission

\begin{tabular}{|c|c|c|c|c|c|}
\hline \multirow[b]{3}{*}{ Variable } & \multicolumn{5}{|c|}{ Propensity score matched, transfused $\leq 44$ hours, titer $\geq 1350$} \\
\hline & \multirow{2}{*}{$\begin{array}{l}\text { Total } \\
(N=421)\end{array}$} & \multirow{2}{*}{$\begin{array}{l}\text { Not transfused } \\
(n=269)\end{array}$} & \multirow{2}{*}{$\begin{array}{l}\text { Transfused } \\
(n=152)\end{array}$} & \multirow{2}{*}{$\frac{\text { Point estimate }}{(95 \% \mathrm{CI})^{*}}$} & \multirow[b]{2}{*}{$P$ value } \\
\hline & & & & & \\
\hline \multicolumn{6}{|l|}{ Disposition, 60 days } \\
\hline Still admitted & $4(1.0)$ & $1(0.4)$ & $3(2.0)$ & $0.20(0.02$ to 2.00$)$ & 0.17 \\
\hline Discharged & $377(89.5)$ & $234(87.0)$ & $143(94.1)$ & (Base outcome) & \\
\hline Death & $40(9.5)$ & $34(12.6)$ & $6(3.9)$ & $3.46(1.40$ to 8.56$)$ & 0.01 \\
\hline \multicolumn{6}{|l|}{$\begin{array}{l}\text { Overall mortality with no } \\
\text { time constraints }\end{array}$} \\
\hline Alive & $381(90.5)$ & $235(87.4)$ & $146(96.1)$ & 3.20 (1.36 to 7.54$)$ & 0.01 \\
\hline Deceased & $40(9.5)$ & $34(12.6)$ & $6(3.9)$ & & \\
\hline \multicolumn{6}{|l|}{$\begin{array}{l}\text { Overall mortality within } \\
28 \text { days after day } 0\end{array}$} \\
\hline Alive & $390(92.6)$ & $243(90.3)$ & $147(96.7)$ & 2.94 (1.12 to 7.74$)$ & 0.03 \\
\hline Deceased & $31(7.4)$ & $26(9.7)$ & $5(3.3)$ & & \\
\hline \multicolumn{6}{|l|}{$\begin{array}{l}\text { Overall mortality within } \\
60 \text { days after day } 0\end{array}$} \\
\hline Alive & $382(90.7)$ & $236(87.7)$ & $146(96.1)$ & 3.11 (1.29 to 7.50$)$ & 0.01 \\
\hline Deceased & $39(9.3)$ & $33(12.3)$ & $6(3.9)$ & & \\
\hline $\begin{array}{l}\text { Length of stay after day } 0, \\
\text { median (IQR), days }\end{array}$ & $5.3(2.9$ to 10.0$)$ & $5.0(2.7$ to 10.0$)$ & 5.7 (3.5 to 9.7$)$ & $-0.57(-2.98$ to 1.85$)$ & 0.65 \\
\hline \multicolumn{6}{|l|}{ Required ICU after day 0} \\
\hline No & $291(69.1)$ & $183(68.0)$ & $108(71.1)$ & 1.10 (0.81 to 1.50$)$ & 0.52 \\
\hline Yes & $130(30.9)$ & $86(32.0)$ & $44(28.9)$ & & \\
\hline $\begin{array}{l}\text { ICU length of stay after } \\
\text { day } 0 \text {, mean } \pm S D \text {, days }\end{array}$ & $10.8 \pm 11.3$ & $10.7 \pm 11.3$ & $11.2 \pm 11.4$ & $-0.52(-4.55$ to 3.50$)$ & 0.80 \\
\hline \multicolumn{6}{|l|}{$\begin{array}{l}\text { Mechanical ventilation } \\
\text { requirement, after } \\
\text { day } 0\end{array}$} \\
\hline No & $347(82.4)$ & $217(80.7)$ & $130(85.5)$ & 1.34 (0.86 to 2.08 ) & 0.20 \\
\hline Yes & $74(17.6)$ & $52(19.3)$ & $22(14.5)$ & & \\
\hline $\begin{array}{l}\text { Mechanical ventilation } \\
\text { time after day } 0 \text { (for } \\
\text { patients who required } \\
\text { ventilation), mean } \pm \\
\text { SD, days }\end{array}$ & $19.8 \pm 19.2$ & $17.9 \pm 15.7$ & $24.2 \pm 25.5$ & $-6.34(-16.72$ to 4.03$)$ & 0.23 \\
\hline \multicolumn{6}{|l|}{$\begin{array}{l}\text { Supplemental oxygen } \\
\text { after day } 0\end{array}$} \\
\hline No & $60(14.3)$ & $50(18.6)$ & $10(6.6)$ & 0.79 (0.75 to 0.84$)$ & $<0.001$ \\
\hline Yes & $361(85.7)$ & $219(81.4)$ & $142(93.4)$ & & \\
\hline $\begin{array}{l}\text { Supplemental oxygen time } \\
\text { after day } 0 \text { (for patients } \\
\text { who required } \\
\text { supplemental oxygen), } \\
\text { median (IQR), days }\end{array}$ & $5.4 \pm 5.8$ & $5.6 \pm 6.4$ & $5.0 \pm 4.8$ & $0.60(-0.55$ to 1.76$)$ & 0.31 \\
\hline \multicolumn{6}{|l|}{ Ventilation status at day 7} \\
\hline Room air & $272(64.6)$ & $172(63.9)$ & $100(65.8)$ & (Base outcome) & \\
\hline Low flow & $38(9.0)$ & $19(7.1)$ & $19(12.5)$ & $0.58(0.29$ to 1.15$)$ & 0.12 \\
\hline High flow/NIPPV & $47(11.2)$ & $34(12.6)$ & $13(8.6)$ & $1.52(0.77$ to 3.01$)$ & 0.23 \\
\hline Mechanical ventilation & $52(12.4)$ & $35(13.0)$ & $17(11.2)$ & $1.20(0.64$ to 2.25$)$ & 0.58 \\
\hline ECMO & $4(1.0)$ & $2(0.7)$ & $2(1.3)$ & $0.58(0.08$ to 4.22$)$ & 0.59 \\
\hline Death & $8(1.9)$ & $7(2.6)$ & $1(0.7)$ & $4.07(0.49$ to 33.99$)$ & 0.20 \\
\hline \multicolumn{6}{|l|}{$\begin{array}{l}\text { Ventilation status at day } \\
\quad 14\end{array}$} \\
\hline Room air & $346(82.2)$ & $214(79.6)$ & $132(86.8)$ & (Base outcome) & \\
\hline Low flow & $4(1.0)$ & $2(0.7)$ & $2(1.3)$ & 0.62 (0.09 to 4.43$)$ & 0.63 \\
\hline High flow/NIPPV & $13(3.1)$ & $10(3.7)$ & $3(2.0)$ & $2.06(0.55$ to 7.69$)$ & 0.28 \\
\hline Mechanical ventilation & $37(8.8)$ & $25(9.3)$ & $12(7.9)$ & 1.29 (0.62 to 2.65$)$ & 0.50 \\
\hline ECMO & $3(0.7)$ & $2(0.7)$ & $1(0.7)$ & $1.23(0.11$ to 13.79$)$ & 0.87 \\
\hline Death & $18(4.3)$ & $16(5.9)$ & $2(1.3)$ & 4.93 (1.09 to 22.38$)$ & 0.04 \\
\hline \multicolumn{6}{|l|}{$\begin{array}{l}\text { Ventilation status at day } \\
28\end{array}$} \\
\hline Room air & $363(86.2)$ & $223(82.9)$ & $140(92.1)$ & & \\
\hline
\end{tabular}


Table 3 (continued)

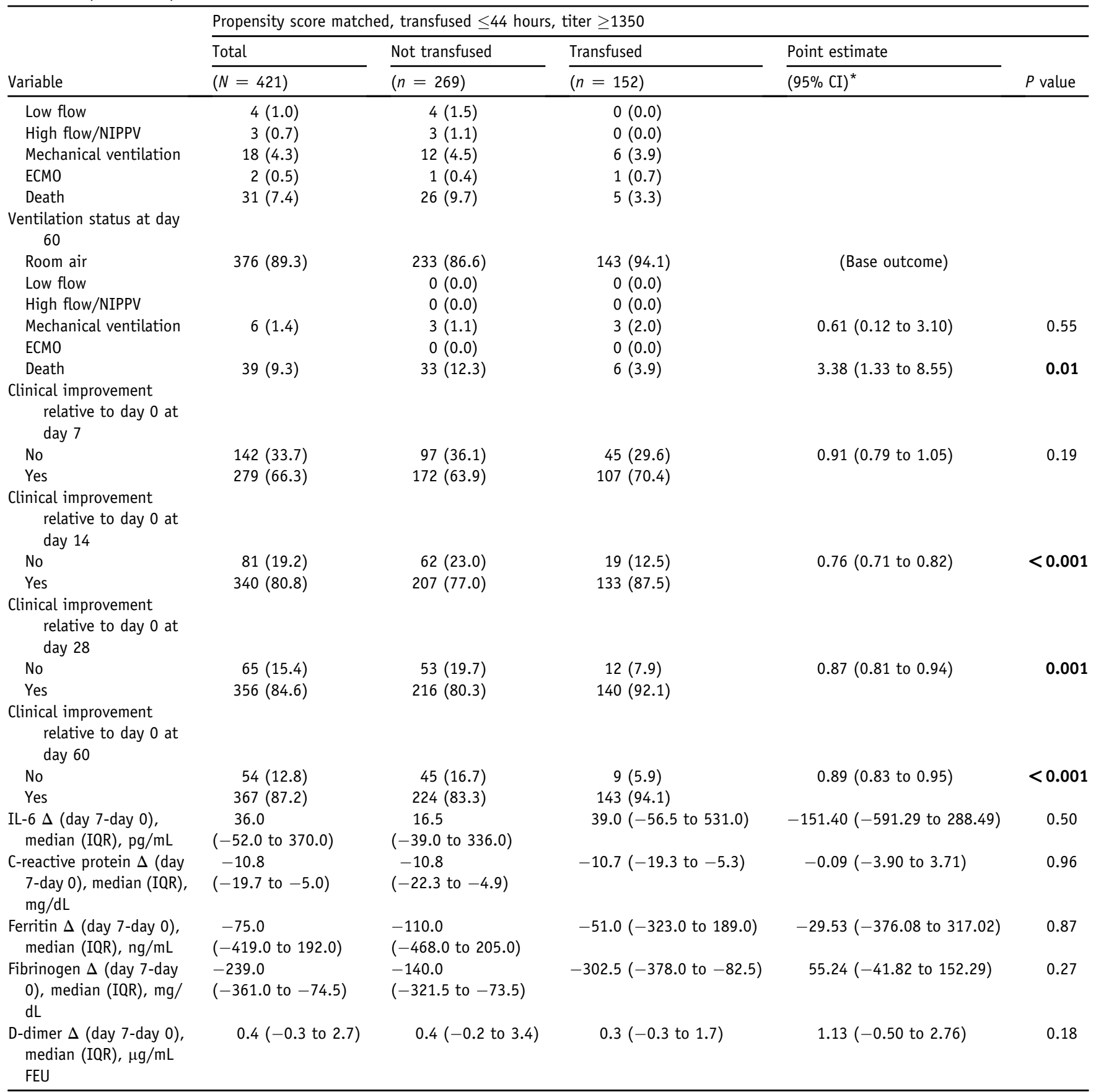

Values are expressed as median (IQR) for continuous variables and $n(\%)$ for categorical variables. Bolded values are statistically significant $(P<0.05)$. *Point estimate obtained from the generalized linear models (for binary and continuous dependent variables) or multinomial logistic regression (for categorical variables), which is risk ratio of outcome in non-transfusion versus transfusion (if categorical outcomes) or coefficient of outcome in nontransfusion versus transfusion (if continuous outcomes).

ECM0, extracorporeal membrane oxygenation; FEU, fibrinogen equivalent unit; ICU, intensive care unit; IQR, interquartile range; NIPPV, noninvasive positive pressure ventilation.

care; the many donor center and blood bank phlebotomists and technologists for dedication to donor and blood safety; Sasha Pejerrey, Adrienne Winston, and Heather McConnell for editorial assistance; Claude Moussa, Heather Patton, and other members of our laboratory information technology team for implementing electronic workflows; Pamela
McShane, Dilzi Mody, and members of the biorepository team for management of patient samples; Christina Talley, Susan Miller, and Mary Clancy for outstanding advice; Zivko Nikolov, Susan Woodard, and Michael Johanson (National Center for Therapeutics Manufacturing, Texas A\&M University) for production of spike protein antigens; 
Table 4 Univariate and Multivariate Cox Regression, Overall Mortality within 28 and 60 Days, for Controls Matched to Cases Who Received Plasma with Titer $\geq 1: 1350$ within 44 Hours of Hospital Admission

\begin{tabular}{|c|c|c|c|c|}
\hline \multirow[b]{3}{*}{ Univariate } & \multicolumn{4}{|l|}{ Within 60 days } \\
\hline & Alive & Deceased & \multicolumn{2}{|l|}{ Unadjusted HR } \\
\hline & $(n=382)$ & $(n=39)$ & $(95 \% \mathrm{CI})$ & $P$ value \\
\hline Transfused & $146(38.2)$ & $6(15.4)$ & (Reference) & \\
\hline Not transfused & $236(61.8)$ & $33(84.6)$ & 3.26 (1.32 to 8.04$)$ & 0.01 \\
\hline Age, median (IQR), years & 51.0 (39.0 to 60.0$)$ & $65.0(59.0$ to 75.0$)$ & $1.08(1.06$ to 1.11$)$ & $<0.001$ \\
\hline $30-39$ & $68(17.8)$ & $0(0.0)$ & & \\
\hline $40-49$ & $83(21.7)$ & $2(5.1)$ & (Reference) & \\
\hline $50-59$ & $104(27.2)$ & $7(17.9)$ & $2.71(0.56$ to 13.24$)$ & 0.22 \\
\hline $60-69$ & $73(19.1)$ & $15(38.5)$ & $7.80(1.74$ to 34.96$)$ & 0.01 \\
\hline $70-79$ & $20(5.2)$ & $9(23.1)$ & 16.08 (3.38 to 76.64$)$ & $<0.001$ \\
\hline$\geq 80$ & $6(1.6)$ & $5(12.8)$ & $26.69(5.03$ to 141.70$)$ & $<0.001$ \\
\hline \multicolumn{5}{|l|}{ Race } \\
\hline White & $250(65.4)$ & $30(76.9)$ & (Reference) & \\
\hline Black & $78(20.4)$ & $5(12.8)$ & 0.55 (0.21 to 1.42$)$ & 0.21 \\
\hline Asian & $27(7.1)$ & $2(5.1)$ & 0.63 (0.15 to 2.77$)$ & 0.54 \\
\hline Other & $13(3.4)$ & $0(0.0)$ & & \\
\hline Unknown & $14(3.7)$ & $2(5.1)$ & $1.18(0.27$ to 5.09$)$ & 0.82 \\
\hline \multicolumn{5}{|l|}{ Ethnicity } \\
\hline Non-Hispanic & $176(46.1)$ & $20(51.3)$ & (Reference) & \\
\hline Hispanic & $201(52.6)$ & $19(48.7)$ & $0.83(0.45$ to 1.53$)$ & 0.56 \\
\hline Unknown & $5(1.3)$ & $0(0.0)$ & & \\
\hline $\begin{array}{l}\text { Body mass index, median (IQR), } \\
\mathrm{kg} / \mathrm{m}^{2}\end{array}$ & 31.6 (28.3 to 36.8$)$ & $30.2(25.9$ to 33.6$)$ & 0.94 (0.89 to 0.99$)$ & 0.02 \\
\hline \multicolumn{5}{|l|}{ Body mass index, $\mathrm{kg} / \mathrm{m}^{2}$} \\
\hline \multicolumn{5}{|l|}{$\begin{array}{l}\text { Body mass index }<30 \text { or } \geq 30 \mathrm{~kg} / \\
\mathrm{m}^{2}\end{array}$} \\
\hline No & $199(52.1)$ & $10(25.6)$ & (Reference) & \\
\hline Yes & $183(47.9)$ & $29(74.4)$ & $2.98(1.41$ to 6.30$)$ & 0.004 \\
\hline \multicolumn{5}{|l|}{ Diabetes } \\
\hline No & $237(62.0)$ & $16(41.0)$ & (Reference) & \\
\hline Yes & $145(38.0)$ & $23(59.0)$ & $2.23(1.26$ to 3.97$)$ & 0.01 \\
\hline \multicolumn{5}{|l|}{ Chronic pulmonary disease } \\
\hline No & $344(90.1)$ & $32(82.1)$ & (Reference) & \\
\hline Yes & $38(9.9)$ & $7(17.9)$ & $1.88(0.84$ to 4.23$)$ & 0.13 \\
\hline \multicolumn{5}{|l|}{ Chronic kidney disease } \\
\hline No & $357(93.5)$ & $34(87.2)$ & (Reference) & \\
\hline Yes & $25(6.5)$ & $5(12.8)$ & 1.93 (0.80 to 4.67$)$ & 0.15 \\
\hline \multicolumn{5}{|l|}{ Hyperlipidemia } \\
\hline No & $281(73.6)$ & $21(53.8)$ & (Reference) & \\
\hline Yes & $101(26.4)$ & $18(46.2)$ & 2.26 (1.19 to 4.29$)$ & 0.01 \\
\hline Coronary disease & & & & \\
\hline No & $367(96.1)$ & $36(92.3)$ & (Reference) & \\
\hline Yes & $15(3.9)$ & $3(7.7)$ & $2.00(0.60$ to 6.59$)$ & 0.26 \\
\hline Baseline outcome group & & & & \\
\hline Room air & $12(3.1)$ & $1(2.6)$ & (Reference) & \\
\hline Supplemental oxygen & $343(89.8)$ & $24(61.5)$ & 0.83 (0.10 to 6.52$)$ & 0.86 \\
\hline Mechanical ventilation & $27(7.1)$ & $14(35.9)$ & 5.03 (0.69 to 36.51$)$ & 0.11 \\
\hline
\end{tabular}


Table 4 (continued)

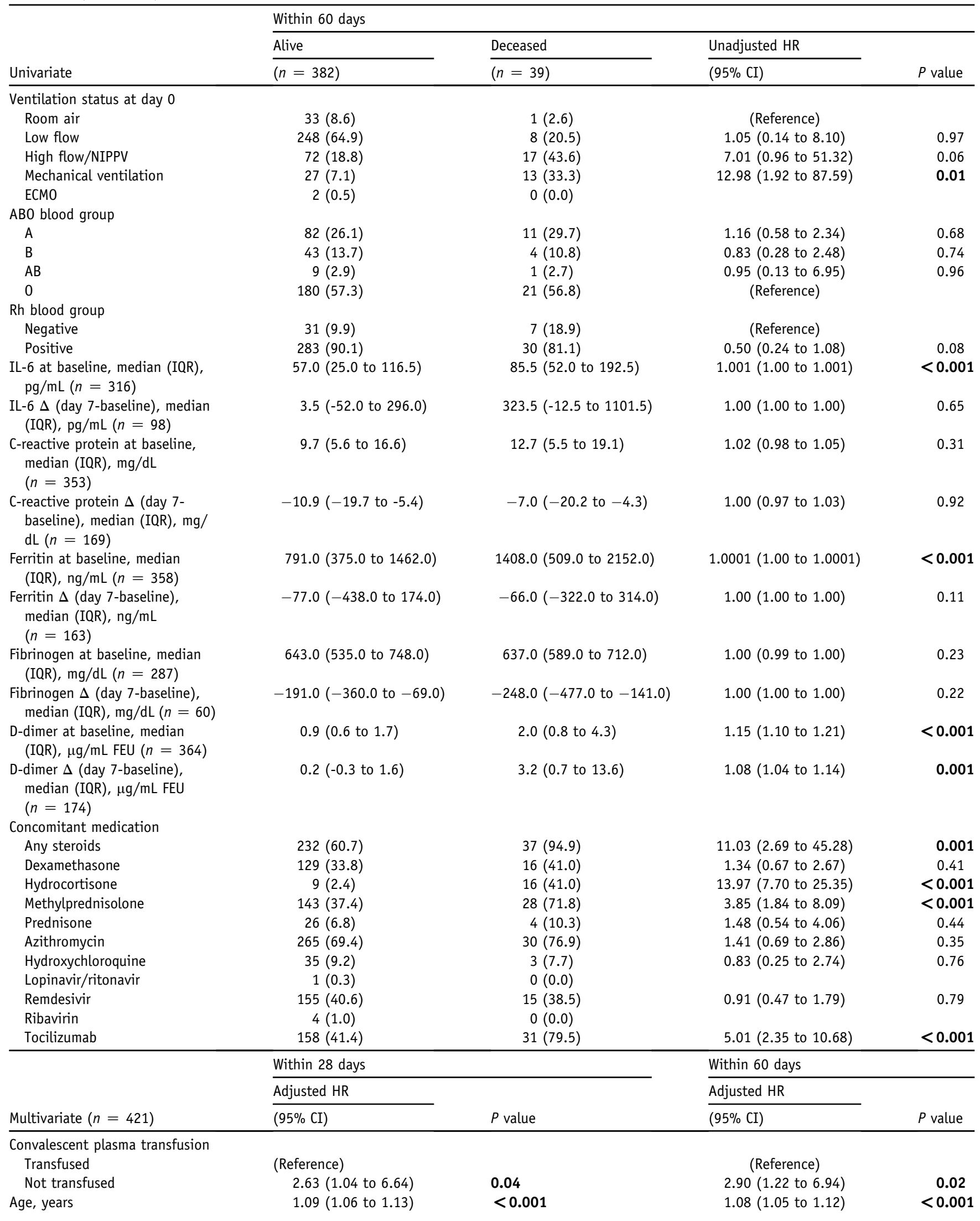


Table 4 (continued)

\begin{tabular}{|c|c|c|c|c|}
\hline \multirow[b]{3}{*}{ Multivariate $(n=421)$} & \multicolumn{2}{|l|}{ Within 28 days } & \multicolumn{2}{|l|}{ Within 60 days } \\
\hline & Adjusted HR & & Adjusted HR & \\
\hline & $(95 \% \mathrm{CI})$ & $P$ value & $(95 \% \mathrm{CI})$ & $P$ value \\
\hline Diabetes & $1.74(0.90$ to 3.38$)$ & 0.10 & 1.87 (1.04 to 3.36$)$ & 0.04 \\
\hline Any steroid & 8.45 (1.78 to 40.03$)$ & 0.01 & 11.16 (2.54 to 48.99$)$ & 0.001 \\
\hline C-statistic & 0.86 & & 0.86 & - \\
\hline
\end{tabular}

Values are expressed as median (IQR) for continuous variables and $n(\%)$ for categorical variables. Bolded values are statistically significant $(P<0.05)$. Steroids and tocilizumab were treated as time-varying covariates in the multivariate model.

ECMO, extracorporeal membrane oxygenation; FEU, fibrinogen equivalent unit; HR, hazard ratio; IQR, interquartile range; NIPPV, noninvasive positive pressure ventilation.

Manuel Hinojosa and Mark Vassallo for rapidly procuring resources; Drs. Marc Boom and Dirk Sostman for support; many generous Houston citizens and businesses for philanthropic support of this ongoing project, including but not limited to: anonymous, Ann and John Bookout III, Carolyn and John Bookout, Ting Tsung and Wei Fong Chao Foundation, Ann and Leslie Doggett, Freeport LNG, the Hearst Foundations, Jerold B. Katz Foundation, C. James and Carole Walter Looke, Diane and David Modesett, the Sherman Foundation, Paula and Joseph C. "Rusty" Walter III, and Aramco Americas; Dr. Jason S. McLellan (University of Texas at Austin) for providing the monoclonal antibody CR3022 and the spike protein expression vectors; the members of the Center for Systems and Synthetic Biology (University of Texas at Austin) for technical assistance; Terumo BCT for supplying blood collection devices and supplies; and Shmuel Shoham, M.D., forsharing a draft study protocol for adaptation early in the study planning phase.

\section{Author Contributions}

E.S. and J.M.M. conceived the project; E.S., P.A.C., E.A.G., D.T.N., B.C., J.C., B.V.L., T.N.E., X.Y., P.Z., J.R., A.S., D.J., and J.G. acquired data; E.S., P.A.C., E.A.G., D.T.N., B.C., J.C., and J.M.M. analyzed data; E.S., P.A.C., E.A.G., D.T.N., and J.M.M. wrote the manuscript; E.S., P.A.C., E.A.G., D.T.N., and J.M.M. prepared figures; C.L., R.J.O., D.W.B., F.M., and J.G. provided scholarly advice; all authors revised the manuscript and gave final approval for publication. J.M.M. is the guarantor of this work and, as such, had full access to all of the data in the study and takes responsibility for the integrity of the data and the accuracy of the data analysis.

\section{Supplemental Data}

Supplemental material for this article can be found at http://doi.org/10.1016/j.ajpath.2020.10.008.

\section{References}

1. COVID-19 Dashboard by the Center for Systems Science and Engineering (CSSE) at Johns Hopkins University (JHU). Baltimore, MD Johns Hopkins University and Medicine, 2020

2. Joyner MJ, Senefeld JW, Klassen SA, Mills JR, Johnson PW, Theel ES, et al: Effect of convalescent plasma on mortality among hospitalized patients with COVID-19: initial three-month experience. medRxiv 2020 [Epub]. doi:10.1101/2020.08.12.20169359

3. Salazar E, Christensen PA, Graviss EA, Nguyen DT, Castillo B, Chen J, Lopez BV, Eagar TN, Yi X, Zhao P, Rogers J, Shehabeldin A, Joseph D, Leveque C, Olsen RJ, Bernard DW, Gollihar J, Musser JM: Treatment of coronavirus disease 2019 patients with convalescent plasma reveals a signal of significantly decreased mortality. Am J Pathol 2020, 190:2290-2303

4. Klassen SA, Senefeld J, Johnson PW, Carter RE, Wiggins CC, Shoham S, Grossman BJ, Henderson JP, Musser JM, Salazar E, Hartman WR, Bouvier NM, Liu STH, Pirofski L-a, Baker SE, Van Helmond N, Wright RS, Fairweather D, Bruno KA, Paneth NS, Casadevall A, Joyner MJ: Evidence favouring the efficacy of convalescent plasma for COVID-19 therapy. medRxiv 2020 [Epub]. doi: 10.1101/2020.07.29.20162917

5. Salazar E, Kuchipudi SV, Christensen PA, Eagar TN, Yi X, Zhao P, Jin Z, Long SW, Olsen RJ, Chen J, Castillo B, Leveque C, Towers DM, Lavinder J, Gollihar JD, Cardona J, Ippolito GC, Nissly RH, Bird IM, Greenawalt D, Rossi RM, Gontu A, Srinivasan S, Poojary IB, Cattadori IM, Hudson PJ, Joselyn N, Prugar L, Huie K, Herbert A, Bernard DW, Dye J, Kapur V, Musser JM: Relationship between anti-spike protein antibody titers and SARS-CoV-2 in vitro virus neutralization in convalescent plasma. bioRxiv 2020 [Epub]. doi: $10.1101 / 2020.06 .08 .138990$

6. Salazar E, Perez KK, Ashraf M, Chen J, Castillo B, Christensen PA, Eubank T, Bernard DW, Eagar TN, Long SW, Subedi S, Olsen RJ, Leveque C, Schwartz MR, Dey M, Chavez-East C, Rogers J, Shehabeldin A, Joseph D, Williams G, Thomas K, Masud F, Talley C, Dlouhy KG, Lopez BV, Hampton C, Lavinder J, Gollihar JD, Maranhao AC, Ippolito GC, Saavedra MO, Cantu CC, Yerramilli P, Pruitt L, Musser JM: Treatment of coronavirus disease 2019 (COVID-19) patients with convalescent plasma. Am J Pathol 2020, 190:1680-1690

7. Salazar E, Kuchipudi SV, Christensen PA, Eagar T, Yi X, Zhao P, Jin Z, Long SW, Olsen RJ, Chen J, Castillo B, Leveque C, Towers D, Lavinder JJ, Gollihar J, Cardona JA, Ippolito GC, Nissly RH, Bird I, Greenawalt D, Rossi RM, Gontu A, Srinivasan S, Poojary I, Cattadori IM, Hudson P, Josleyn NM, Prugar L, Huie KE, Herbert AS, Bernard DW, Dye JM, Kapur V, Musser JM: Convalescent plasma anti-SARS-CoV-2 spike protein ectodomain and receptor binding domain IgG correlate with virus neutralization. J Clin Invest 2020, 130:6728-6738 
8. Barone P, DeSimone RA: Convalescent plasma to treat coronavirus disease 2019 (COVID-19): considerations for clinical trial design. Transfusion 2020, 60:1123-1127

9. Liu STH, Lin H-M, Baine I, Wajnberg A, Gumprecht JP, Rahman F, Rodriguez D, Tandon P, Bassily-Marcus A, Bander J, Sanky C, Dupper A, Zheng A, Altman DR, Chen BK, Krammer F, Mendu DR, Firpo-Betancourt A, Levin MA, Bagiella E, Casadevall A, CordonCardo C, Jhang JS, Arinsburg SA, Reich DL, Aberg JA, Bouvier NM: Convalescent plasma treatment of severe COVID-19: a matched control study. Nat Med 2020, 26:1708-1713

10. Rosenbaum PR, Rubin DB: The central role of the propensity score in observational studies for causal effects. Biometrika 1983, 70:41-55

11. Hastie T, Tibshirani R, Wainwright M: Statistical Learning with Sparsity: The Lasso and Generalizations. Boca Raton, FL: CRC Press, 2015

12. Lasso SS: Stata Reference Manual: Release 16. College Station, TX: Stata Press, 2020

13. Youden WJ: Index for rating diagnostic tests. Cancer 1950, 3:32-35

14. Eckhardt CM, Cummings MJ, Rajagopalan KN, Borden S, Bitan ZC, Wolf A, Kantor A, Briese T, Meyer BJ, Jacobson SD, Scotto D, Mishra N, Philip NM, Stotler BA, Schwartz J, Shaz B, Spitalnik SL, Eisenberger A, Hod EA, Justman J, Cheung K, Lipkin WI, O’Donnell MR: Evaluating the efficacy and safety of human anti-SARS-CoV-2 convalescent plasma in severely ill adults with COVID-19: a structured summary of a study protocol for a randomized controlled trial. Trials 2020, 21:499

15. Gharbharan A, Jordans CCE, GeurtsvanKessel C, den Hollander JG, Karim F, Mollema FPN, Stalenhoef JE, Dofferhoff A, Ludwig I, Koster A, Hassing R-J, Bos JC, van Pottelberge GR, Vlasveld IN, Ammerlaan HSM, Segarceanu E, Miedema J, van der Eerden M, Papageorgiou G, te Broekhorst P, Swaneveld FH, Katsikis PD, Mueller Y, Okba NMA, Koopmans MPG, Haagmans BL, Rokx C, Rijnders B: Convalescent plasma for COVID-19: a randomized clinical trial. medRxiv 2020 [Epub]. doi:10.1101/2020.07.01.20139857

16. Hegerova L, Gooley T, Sweerus KA, Maree CL, Bailey N, Bailey M, Dunleavy V, Patel K, Alcorn K, Haley NR, Johnsen JM, Konkle BA,
Lahti AC, Alexander ML, Goldman JD, Lipke A, Lim SJ, Sullivan MD, Pauk JS, Pagel JM: Use of convalescent plasma in hospitalized patients with Covid-19: case series. Blood 2020, 136: $759-762$

17. Li L, Zhang W, Hu Y, Tong X, Zheng S, Yang J, Kong Y, Ren L, Wei Q, Mei H, Hu C, Tao C, Yang R, Wang J, Yu Y, Guo Y, Wu X, Xu Z, Zeng L, Xiong N, Chen L, Wang J, Man N, Liu Y, Xu H, Deng E, Zhang X, Li C, Wang C, Su S, Zhang L, Wang J, Wu Y, Liu Z: Effect of convalescent plasma therapy on time to clinical improvement in patients with severe and life-threatening COVID-19: a randomized clinical trial. JAMA 2020, 324:460-470

18. Agarwal A, Mukherjee A, Kumar G, Chatterjee P, Bhatnagar T, Malhotra P, et al: Convalescent plasma in the management of moderate COVID-19 in India: an open-label parallel-arm phase II multicentre randomized controlled trial (PLACID Trial). BMJ 2020, 371:m3939

19. Avendano-Sola C, Ramos-Martinez A, Munez-Rubio E, RuizAntoran B, Malo de Molina R, Torres F, et al: Convalescent plasma for COVID-19: a multicenter, randomized clinical trial. medRxiv 2020 [Epub]. doi:10.1101/2020.08.26.20182444

20. Balcells ME, Rojas L, Le Corre N, Martínez-Valdebenito C, Ceballos ME, Ferrés M, Chang M, Vizcaya C, Mondaca S, Huete Á, Castro R, Sarmiento M, Villarroel L, Pizarro A, Ross P, Santander J, Lara B, Ferrada M, Vargas-Salas S, Beltrán-Pavez C, Soto-Rifo R, Valiente-Echeverría F, Caglevic C, Mahave M, Selman C, Gazitúa R, Briones JL, Villarroel-Espindola F, Balmaceda C, Espinoza MA, Pereira J, Nervi B: Early anti-SARS-CoV-2 convalescent plasma in patients admitted for COVID-19: a randomized phase II clinical trial. medRxiv 2020 [Epub]. doi:10.1101/2020.09.17.20196212

21. Bohn MK, Hall A, Sepiashvili L, Jung B, Steele S, Adeli K: Pathophysiology of COVID-19: mechanisms underlying disease severity and progression. Physiology (Bethesda) 2020, 35:288-301

22. Casadevall A, Pirofski LA: The convalescent sera option for containing COVID-19. J Clin Invest 2020, 130:1545-1548 